\title{
Optimizing irrigation and determining the most sensitive development stage to drought in barley (Hordeum vulgare L.) in a semi-arid environment
}

\author{
Leila Romdhane ${ }^{1}$, Nicola Dal Ferro ${ }^{2}$, Amor Slama ${ }^{3 *}$, Leila Radhouane ${ }^{1}$ \\ ${ }^{1}$ University of Carthage, National Institute of Agronomic Research of Tunisia, Hédi Karray Street, 2049 Ariana, Tunisia \\ ${ }^{2}$ University of Padova, Department of Agronomy, Food, Natural Resources, Animals and Environment, Viale \\ dell'Università 16, 35020 Legnaro, Padova, Italy \\ ${ }^{3}$ University of Carthage, Faculty of Science, 7021 Jarzouna-Bizerte, Tunisia
}

\begin{abstract}
Rising temperatures and increasing water scarcity, which are already important issues, are expected to intensify in the near future due to global warming. Optimizing irrigation in agriculture is a challenge. Understanding the response of crop development stages to water deficit stress provides an opportunity for optimizing irrigation. Here we studied the response of two barley varieties (Rihane, Martin), to water deficit stress at three development stages (tillering, stem elongation, and heading) by measuring water status and grain yield components in a field experiment in Tunisia. The three stages were selected due to their importance in crop growth and grain development. Water deficit stress was initiated by withholding water for 21 days at the three stages with subsequent re-watering. Water deficit led to a progressive decrease in leaf water potential. In both varieties, heading was the stage most sensitive to water deficit. Leaf water potential measurements indicated that water deficit stress was more severe during heading, which to some extent may have influenced the comparison between growth stages. During heading, the number of ears per plant and weight of a thousand grains were reduced by more than $70 \%$ and $50 \%$, respectively compared with stress at tillering. Comparison of yield components showed differences between the two barley varieties only when the water deficit was produced during the tillering stage.
\end{abstract}

Keywords: barley, climate change, crop development stage, grain yield components, leaf water potential, water deficit.

\section{Introduction}

Climate change has detrimental impacts on agriculture worldwide (Stevanović et al. 2016). The Mediterranean region, described as the hot-spot of climate change (Rochdane et al. 2014), is vulnerable to changes in climate, with a predicted decrease in crop production(Olesen et al. 2011). Several models envisaged a shorter growing season, increased heat, and water deficit stress in southern Mediterranean regions, which will reduce harvestable yields in both spring (4-40\%) and winter crops (4-17\%), counteracting the gains due to increased atmospheric $\mathrm{CO}_{2}$ concentration (Giannakopoulos et al. 2009, Moriondo et al. 2011, Gammans et al. 2017).

The main rainfed crops grown in Tunisia are cereals (mainly wheat - Triticum durum Desf. - and barley - Hordeum vulgare L.), occupying about two-thirds of total culti- vated areas and accounting for $16 \%$ of the agricultural production value. Cereal yields can vary significantly from year to year due to unpredictable and largely irregular rainfall patterns (Deghaïs et al. 2007). This situation will become more critical against the background of a changing climate, which already impacts agricultural production around the globe. The production of cereals, which are the most strategic and vital crops in Tunisia, is projected to be severely compromised by the combined effects of high temperature and water deficit (Perniola et al. 2015). Recent studies have shown that already by 2020, rainfall is expected to drop by between 5 and $20 \%$ in Tunisia, while by 2100 temperatures could rise between 2 and $4{ }^{\circ} \mathrm{C}$ (Mougou et al. 2011). These changes could contribute to soil degradation as a result of drought and other restrictive factors (Sultan 2012, Balkovič

\footnotetext{
* Corresponding author e-mail: slamaamor@yahoo.fr

Nicola Dal Ferro and Amor Slama contributed equally in writing and reviewing of this paper.
} 
et al. 2018). In agronomy, to solve the issues of water shortage we have to cultivate low water requiring crops or apply less water to the crop (Bashir et al. 2017). In addition to being affected by scarce rainfall and its patchy distribution during the cereal season, yield depends on fertilization and the ability of selected varieties or species to cope with water deficits. Under water deficit conditions, plants present several morpho-physiological and biochemical changes as part of their strategies to reduce water deficit stress effects (Slama et al. 2018), which has led farmers and researchers to look for alternative varieties, such as the old ones, in which lower yields can be offset with better adaptation to the environment (Malek and Verburg 2018).

Barley is the second most cultivated cereal crop in Tunisia after durum wheat. Barley yield components depend on the different development stages (vegetative period, heading, anthesis, and post-anthesis), on the availability of assimilates, on genotype, and on the amount of water supplied (Tambussi et al. 2005, Al-Ajlouni et al.2016).Water deficit stress can be mitigated by supplementary irrigation, especially during the critical development phases (Meng et al. 2017, Wang 2017). Moreover, the response of crop development stages to water deficit stress is apparently more important than the quantity of water supplied (Morison et al. 2008). It is important to adopt a water-saving management regime (Zhang et al. 2019). In this context, attention is increasingly being paid to old varieties as alternatives to recent ones. It is suggested that their genetic heritage could be a resource for actual and future adaptation to changing climatic conditions. However, to our knowledge only a few have studied the growth behavior of recent and old varieties under water deficit stress (Cattivelli et al. 2011).

In this context, the aim of this study was to determine the development stage most sensitive to water deficit conditions and to assess whether the sensitive period differs among varieties in relation to drought. Two barley varieties, an old (Martin) and a recent one (Rihane) that are both recognized as being drought-tolerant, were selected and submitted to episodic water deficit stress and then re-irrigated at different development stages: (i) to determine the most critical period under water deficit, (ii) to quantify the effect of this constraint on the recent and old variety.

\section{Materials and methods}

\section{Study area}

The study was conducted at the experimental farm of the National Institute of Agronomic Research of Tunisia (INRAT) at Ariana ( $\left.36^{\circ} 51^{\prime} \mathrm{N}, 10^{\circ} 11^{\prime} \mathrm{E}\right)$, in northern Tunisia. The local climate is semi-arid, with a mean annual rainfall of about $320 \mathrm{~mm}$ and a mean annual temperature of $20.2^{\circ} \mathrm{C}$, ranging from the lowest average monthly temperature in January/February, $11.5^{\circ} \mathrm{C}$, to the highest in July-August, $27^{\circ} \mathrm{C}$ (Fig.1). The soil is a silt loam (sand 23.5\%, silt $55.1 \%$, clay $21.4 \%$ ), with apH of 8.2 and soil organic matter content of $2 \%$. The soil water retention capacity is

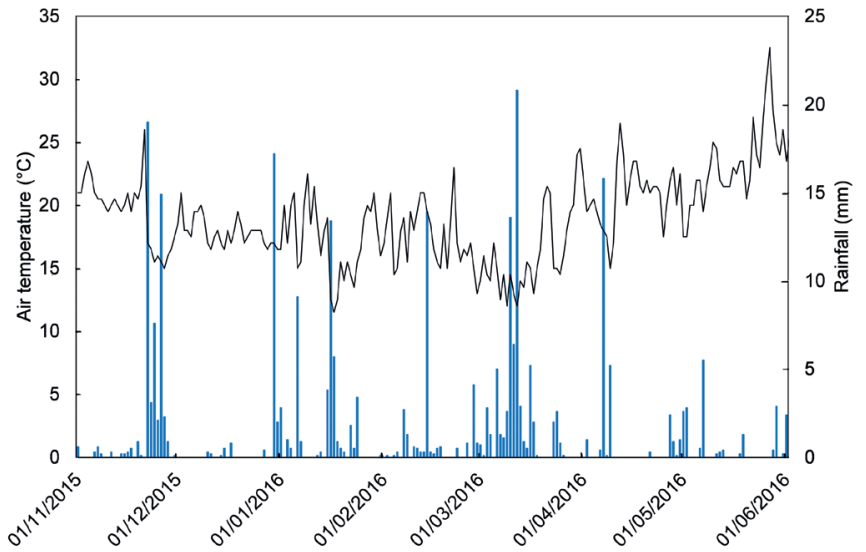

Fig. 1. Daily mean of air temperature $\left({ }^{\circ} \mathrm{C}\right)$ and rainfall $(\mathrm{mm})$ during the crop season (from November 2015 to June 2016).

$0.30 \mathrm{~kg} \mathrm{~kg}^{-1}$ at $-0.05 \mathrm{MPa}$, and $0.20 \mathrm{~kg} \mathrm{~kg}^{-1}$ at $-1.5 \mathrm{MPa}$. Additional information was already reported in Romdhane et al. (2016).

\section{Plant growth and water deficit stress}

The experiment was conducted in the 2015-2016 cropping season. Two barley (Hordeum vulgare L.) varieties, Martin and Rihane, were selected for the study. These varieties cover roughly $35 \%$ of total barley cultivation in Tunisia (Ouji et al. 2018). Martin is an old six-row variety developed in Algeria in 1931. Martin is early maturing, has moderate yield $\left(2.7 \mathrm{t} \mathrm{ha}^{-1}\right)$, good resistance to water deficit stress (Deghaïs et al. 2007, Ouji et al. 2018). Rihane is also a six-row variety. It was released by the International Center for Agricultural Research in the Dry Areas (ICARDA) and introduced in Tunisia in 1987. Rihane is widely cultivated in Tunisia because of its early maturity, high yield $\left(3.56 \mathrm{t} \mathrm{ha}^{-1}\right)$, and resistance to water deficit stress and fungal diseases. Permanent wilting point in barley ranges from -1.8 MPa to $-1.5 \mathrm{MPa}$ (Mansouri and Radhouane 2015, Ouji et al. 2018).

The seedbed was prepared in the same way for both barley varieties, with autumn ploughing at $0.3 \mathrm{~m}$ depth, followed by harrowing at $0.2 \mathrm{~m}$ just before sowing. Sowing was on November 15, 2015. Each plot was planted in four $2 \mathrm{~m}$-long rows, spaced $0.25 \mathrm{~m}$ apart, and an area of $2 \mathrm{~m}^{2}$ perplot at a density of 400 seeds $\mathrm{m}^{-2}$ in four replicates. Fertilization consisted of two applications of ammonium-nitrate $(\mathrm{N}$ $=33 \%): 100 \mathrm{~kg} \mathrm{~N} \mathrm{ha}^{-1}$ at sowing and $100 \mathrm{~kg} \mathrm{~N} \mathrm{ha}^{-1}$ at four leaf stage, during tillering.

The experiment was conducted in two adjacent plotsas completely randomized design for each trial: water deficit stress and control (no water deficit) trials. Each trial was organized in 24 plots ( 2 varieties $\times 3$ stages $\times 4$ replicates), separated $1.5 \mathrm{~m}$ apart on each side to minimize the effect of lateral water movement. Water deficit was initiated by withholding irrigation for 21 days during tillering (Zadoks scale $=24$ ), stem elongation (Zadoks scale $=32$ ), and heading (Zadoks scale $=51)$ (Fig. 1). The twovarieties have similar growth stages and water deficit treatment was not influenced by differences in development. At the end of the stress, 
plots were re-watered to the control level. Control plots were maintained at $0.30 \mathrm{~kg} \mathrm{~kg}^{-1}$ of soil water content (about - 0.05 $\mathrm{MPa}$ ) throughout the experiment. Manual irrigation was applied by assessing soil moisture in the $0-50 \mathrm{~cm}$ soil layer, which was measured every week by gravimetric method. If rain seemed likely, all plots were covered with transparent plastic film to prevent variations in moisture content.As a consequence, radiation, air humidity and temperature also differed from natural atmospheric conditions during the periods of soil and vegetation cover.

\section{Soil moisture and plant water status}

Soil moisture and leaf water potential were measured on day 1 and every week thereafter during the 21-day stress (D1: 1 day of dry, D7: 7 days of dry, D14: 14 days of dry, D21: 21 days of dry) (Figs. 2 and 3). To measure soil moisture, four bulk samples were taken from different areas in the middle of each plot along the $0-50 \mathrm{~cm}$ depth, wrapped in bags, and immediately transferred to the laboratory. Then, $50 \mathrm{~g}$ fresh soil of each replicate was placed in aluminum cans and dried in an oven at $110^{\circ} \mathrm{C}$ for 72 hours for dry weight determination.

Leaf water potential was determined by the pressure chamber method according to Scholander et al. (1961), and expressed in MPa. It was measured with a Model 1000 Pressure Chamber (PMS Instrument Company, Albany, USA) on the different dates (D1, D7, D14 and D21). Measurements of leaf water potential were always conducted on the fully developed flag leaf on four randomly selected plants of the two middle rows and from the two water treatments, between 10:00 a.m. and 12:00 noon.
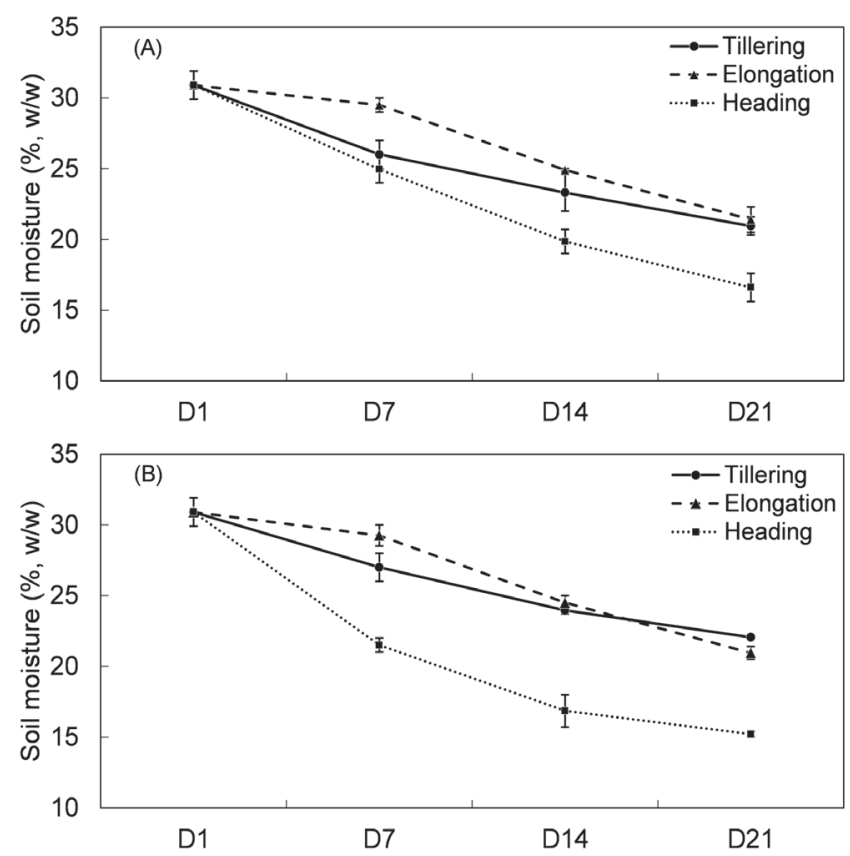

Fig. 2. Gravimetric soil moisture (\%) dynamics in water deficit stress treatments according to days of dry (D1, D7, D14, D21) at different development stages in Rihane (A) and Martin (B) barley varieties. (Variety $\times$ Stage $\times$ Days of dry; $\mathrm{P}<0.05$, four replicates). Error bars \pm standard error. D1:1 day of dry, D7: 7 days of dry,D14: 14 days of dry, D21: 21 days of dry.
At maturity, number of ears per plant (NEP), number of grains per ear (NGE), and thousand grains weight (WTG) were measured in both control and water deficit plots.

\section{Statistical analysis}

Changes in soil moisture and leaf water potential between the two varieties were evaluated using repeated measure ANOVA. Measurements taken over the four time points $(1,7,14,21$ days) during the 21 -day stress period were compared in the two varieties and the three developmental stages (tillering, elongation, and heading). In addition, NEP, NGE, and WTG, were compared using two-way ANOVA, by treating variety and developmental stage as fixed factors. ANOVA assumptions of normality and homogeneity of variance were tested for all parameters using the Shapiro-Wilk test and the Bartlett test, respectively. Significant differences between means were differentiated with a post-hoc Student-Newman-Keuls test $(\mathrm{P}<0.05)$. Statistical analyses were performed using STAT-ITCF version 5 software.

\section{Results}

\section{Variation of soil moisture and leaf water potential}

The decreases in soil moisture throughout the drying cycle are shown in Fig. 2. For both cultivars Rihane and Martin, soil moisture evolved differently depending on the development stage that was affected by water deficit stress. In particular, soil moisture during stem elongation was generally higher than in both tillering and heading until D14 (i.e., after 14 days of dry conditions), whereas the differentiation was reduced at D21 when significant differences were observed between heading and the other two development stages, i.e. tillering and stem elongation, under water deficit conditions. In contrast, no significant differences were observed in soil moisture between varieties (Tab. 1).

Since conditions were similar for both barley varieties (e.g., soil, evaporative surface, sowing density), the differences that were observed in terms of soil moisture were mainly due to the development stage and transpiration of each variety. Indeed, both for Rihane and Martin varieties, soil moisture changes differed depending on development stage. Although the water deficit period was the same for all stages, the permanent wilting point $\left(-1.5 \mathrm{MPa}, 0.20 \mathrm{~kg} \mathrm{~kg}^{-1}\right)$ was reached only during the heading stage. Wilting point was earlier for Martin (before D14), while the Rihane variety reached it after D14 (Fig. 2). Both varieties appeared to absorb more water at the tillering stage than at the elongation stage during the first 15 days of water deficit stress. After this first period, the decrease in soil moisture was similar for the two stages, although more pronounced during stem elongation.

The leaf water potential in the control treatment was similar between varieties, being $-0.65 \mathrm{MPa}( \pm 0.05$ s.e. $)$ and $-0.70 \mathrm{MPa}( \pm 0.03$ s.e.) in Rihane and Martin at D1 tillering, and slightly decreasing until minimum values of -1.1 $\mathrm{MPa}( \pm 0.05$ s.e. $)$ and $-0.7 \mathrm{MPa}( \pm 0.00$ s.e. $)$ at $\mathrm{D} 21$, respec- 
Tab. 1. Analysis of variance for soil moisture and leaf water potential. Abbreviations: $\mathrm{df}=$ degree of freedom, $\mathrm{SS}=$ sum of squares, $\mathrm{MS}=$ mean square, F = Fisher test. Development stages: tillering, stem elongation, and heading. Cultivars: Rihane and Martin. Days of dry: D1: 1 days of dry, D7: 7 days of dry, D14: 14 days of dry, D21: 21 days of dry.

\begin{tabular}{|c|c|c|c|c|c|c|}
\hline \multirow{2}{*}{$\begin{array}{l}\text { Source } \\
\text { Soil moisture }\end{array}$} & & df & SS & MS & $\mathrm{F}$ & P-value \\
\hline & & & & & & \\
\hline \multirow[t]{3}{*}{ Main Effects } & Variety & 1 & 3.20 & 3.20 & 1.8 & 0.224 \\
\hline & Stage & 2 & 176.44 & 88.22 & 50.6 & $<0.001$ \\
\hline & Days of dry & 3 & 889.35 & 296.45 & 236.8 & $<0.001$ \\
\hline \multirow[t]{4}{*}{ Interaction } & Variety $\times$ Stage & 2 & 14.39 & 7.20 & 4.1 & 0.008 \\
\hline & Variety $\times$ Days of dry & 3 & 1.94 & 0.65 & 0.5 & 0.677 \\
\hline & Stage $\times$ Days of dry & 6 & 70.77 & 11.80 & 9.4 & $<0.001$ \\
\hline & Variety $\times$ Stage $\times$ Days of dry & 6 & 6.39 & 1.06 & 0.8 & 0.548 \\
\hline \multicolumn{7}{|c|}{ Leaf water potential } \\
\hline \multirow{3}{*}{ Main Effects } & Variety & 1 & 0.48 & 0.48 & 102 & $<0.001$ \\
\hline & Stage & 2 & 63.30 & 31.65 & 6703 & $<0.001$ \\
\hline & Days of dry & 3 & 15.42 & 5.14 & 851 & $<0.001$ \\
\hline \multirow[t]{4}{*}{ Interaction } & Variety $\times$ Stage & 2 & 0.23 & 0.11 & 24 & $<0.001$ \\
\hline & Variety $\times$ Days of dry & 3 & 0.22 & 0.08 & 12 & $<0.001$ \\
\hline & Stage $\times$ Days of dry & 6 & 8.70 & 1.45 & 240 & $<0.001$ \\
\hline & Variety $\times$ Stage $\times$ Days of dry & 6 & 0.44 & 0.07 & 12 & $<0.001$ \\
\hline
\end{tabular}

tively. Similar dynamics were observed at elongation, when Rihane and Martin slightly decreased leaf water potential from -1.1 ( \pm 0.03 s.e.) at $\mathrm{D} 1$ to $-1.2( \pm 0.04$ s.e. $)$ at $\mathrm{D} 21$, on average, as well as at heading, when on average both varieties reduced it as follows: $-1.8 \mathrm{MPa}( \pm 0.05$ s.e. $)$ at $\mathrm{D} 1>$ $-2.0 \mathrm{MPa}( \pm 0.08$ s.e. $)$ at $\mathrm{D} 7>-2.2 \mathrm{MPa}( \pm 0.03$ s.e. $)$ at $\mathrm{D} 14$ $>-2.3 \mathrm{MPa}( \pm 0.04$ s.e. $)$ at $\mathrm{D} 21$. The decrease in leaf water potential $(\Psi \mathrm{h})$ according to soil drying conditions for both varieties and during the different stages are shown in Fig. 3. Leaf water potential at the tillering stage was significantly higher $(\mathrm{P}<0.001$, Tab. 1$)$ than at the other two stages. Martin and Rihane showed average values of -0.92 and -0.89 $\mathrm{MPa}$, respectively, which decreased to -1.36 and $-1.23 \mathrm{MPa}$, and -2.93 and $-2.66 \mathrm{MPa}$, during elongation and heading. Despite differences being observed in barley growth stages, similar $\Psi$ h dynamics were observed in tillering and elongation. In contrast, a strong $\Psi \mathrm{h}$ reduction was found during heading, highlighting firstly its gradual decrease at soil moisture $>20 \%$, thereafter a sharp reduction at values close to wilting point when leaf water potential reached minimum values of -4.10 and $-3.88 \mathrm{MPa}$ in Martin and Rihane, respectively.

The regressions highlight similar crop response in the two varieties, especially during tillering and elongation (Fig. 4). Increasing differences were observed at heading stage (Fig. 4C), when the Martin variety reached similar $\Psi$ h to those recorded in Rihane, but in drier soil conditions. For instance, during tillering and elongation a slight leaf water potential reduction was observed at increasing drought: a $10 \%$ decrease in soil moisture (from $30 \%$ to $20 \%$ ) induced only $0.5 \mathrm{MPa} \Psi \mathrm{h}$ average changes (Fig.4A, 4B), whereas the same difference in soil moisture caused $\Psi$ h to be reduced to 1.2 $\mathrm{MPa}$ in heading. These results were also emphasized by
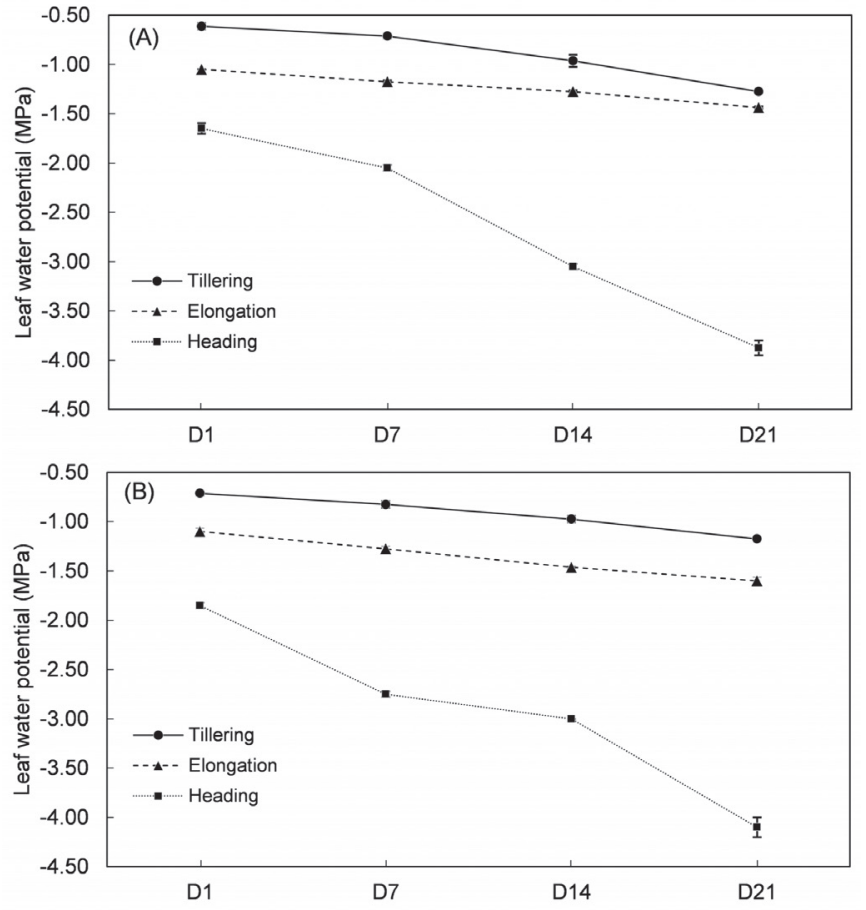

Fig. 3. Leaf water potential (MPa) dynamics in water deficit stress treatments according to days of dry (D1, D7, D14, D21) at different development stages in Rihane (A) and Martin (B) barley varieties. (Stage $\times$ Days of dry; $\mathrm{P}<0.05$, four replicates). Error bars \pm standard error. D1:1 day of dry, D7: 7 days of dry, D14: 14 days of dry, D21: 21 days of dry.

large variations between maximum and minimum leaf water potential values during the water deficit stress treatment, which showed: (i) higher variations in heading, followed by tillering and finally elongation, (ii) negligible changes between varieties (Tab. 2). 
Tab. 2. Percentage decrease rate $\left(1-\left(\Psi \mathrm{h}_{\min } / \Psi \mathrm{h}_{\max }\right) \times 100\right)$ of leaf water potential $(\Psi \mathrm{h})$ between maximum and minimum values for two barley varieties, Rihane and Martin.

\begin{tabular}{lll}
\hline \multirow{2}{*}{ Stages } & \multicolumn{2}{c}{ Variety } \\
\cline { 2 - 3 } & Rihane & Martin \\
\hline Tillering & $49.1 \%$ & $47.0 \%$ \\
Elongation & $27.0 \%$ & $27.0 \%$ \\
Heading & $57.4 \%$ & $55.0 \%$ \\
\hline
\end{tabular}
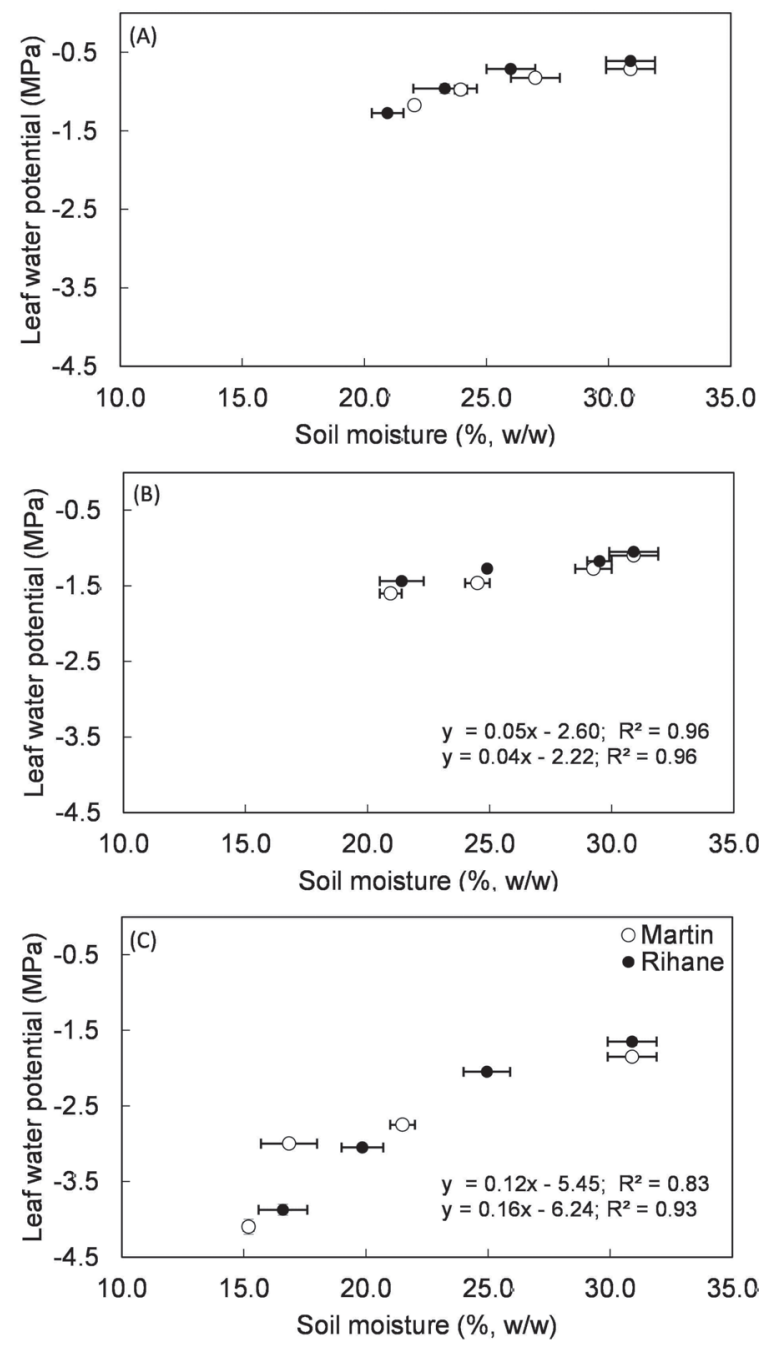

Fig. 4. Regressions between soil moisture and leaf water potential for the two barley varieties (Martin, Rihane) at different stages of water deficit stress: tillering (A), elongation (B), and heading (C).

\section{Variation of yield components}

At the end of each drying cycle, barley was re-irrigated and yield components were measured at harvest. Barley yield has two major components, i.e. grain number and grain weight (Al-Ajlouni et al. 2016); it is hence critical to study the number of ears per plant, number of grains per ear, and weight of a thousand grains.

Analysis of variance indicated that both variety and stage had significant effects $(\mathrm{P}<0.05)$ on ear number per plant (NEP) (Tab. 3), which ranged between 1.10 in Martin at heading and 5.00 in Rihane at tillering. However, the main differences were observed between water deficit stress stages that always differed from one another, whereas varieties at the same stage of water deficit stress showed differences only at tillering. The variation in NEP, according to the time of water stress application (development stage) and variety, showed that when water deficit was induced at a later stage, NEP was lower; the heading stage thus appeared to be the most sensitive to water deficit stress, which can be quantified as $-76 \%$ with respect to the control treatment.

Mean grain number per ear (NGE) was similar for the two varieties (Tab. 3), although with a tendency to higher NGE in Martin in the control treatment and with water deficit stress at tillering only. However, significant differences in water deficit stages were observed between tillering (37.0, on average) and both elongation and heading (17.2, on average). As a result, it can be stated that NGE was more affected when the water deficit stress was induced late, during the elongation and heading stages, than in the early period, during tillering. The period least sensitive to water deficit was the tillering stage, with NGE values twice as high as those for the heading stage.

A significant reduction in weight of a thousand grains (WTG)was also observed according to the stage of the water deficit reached. When water deficit stress was induced at a later stage, the WTG reduced significantly from 42.4 $\mathrm{g}$ at tillering, to $28.9 \mathrm{~g}$ at elongation, and 20.55 at heading. As also observed for other parameters, the heading stage appeared more sensitive than the tillering stage, with a reduction of 50\%. Contrarily to NEP, WTG was significantly higher in Martin (44.4 g) than in Rihane (40.4) when water deficit stress was induced during tillering (Tab. 3).

Tab. 3. Comparison of number of ears per plant (NEP) and grains per ear (NGE), and weight of a thousand grains (WTG) (two-way ANOVA, varieties $\times$ stage) for two barley varieties, Rihane and Martin. Different letters (a, b, c, d) indicate significant differences according to Student-Newman-Keuls test at $\mathrm{P}<0.05 \pm$ standard error. Control treatment (without water deficit stress) was not included in the statistical analysis.

\begin{tabular}{llcccc}
\hline & & Control & Tillering & Elongation & Heading \\
\hline NEP & Rihane & $6.25 \pm 0.37$ & $5.00 \pm 0.36 \mathrm{a}$ & $2.40 \pm 0.056 \mathrm{c}$ & $1.40 \pm 0.15 \mathrm{~d}$ \\
& Martin & $4.35 \pm 0.15$ & $3.6 \pm 0.16 \mathrm{~b}$ & $2.20 \pm 0.17 \mathrm{c}$ & $1.10 \pm 0.06 \mathrm{~d}$ \\
\multirow{2}{*}{ NGE } & Rihane & $35.25 \pm 1.44$ & $35.60 \pm 1.36 \mathrm{a}$ & $17.5 \pm 0.28 \mathrm{~b}$ & $17.9 \pm 2.18 \mathrm{~b}$ \\
& Martin & $42.25 \pm 2.17$ & $38.4 \pm 3.25 \mathrm{a}$ & $14.4 \pm 1.83 \mathrm{~b}$ & $18.9 \pm 3.79 \mathrm{~b}$ \\
\multirow{2}{*}{ WTG } & Rihane & $40.25 \pm 0.85$ & $40.4 \pm 0.48 \mathrm{~b}$ & $28.8 \pm 0.89 \mathrm{c}$ & $20.0 \pm 0.40 \mathrm{~d}$ \\
& Martin & $46.50 \pm 0.65$ & $44.4 \pm 0.25 \mathrm{a}$ & $29.0 \pm 0.83 \mathrm{c}$ & $21.1 \pm 0.36 \mathrm{~d}$ \\
\hline
\end{tabular}




\section{Discussion}

Water deficit is one of the most constraining factors for the growth, development and yields of plants in arid and semi-arid regions of the world (Ben Naceur et al. 2018). In this study, water deficit stress induced a decrease in leaf water potential. This reduction depends on the development stage and plant growth conditions. The exposure of barley to a drying cycle showed a highly significant variation between the three development stages and two studied varieties. According to previous studies, plant behavior depends on the variety, duration and intensity of the water deficit stress, but also its timing (Tardieu 2013). Leaf water potential decreased proportionally with reductions in soil moisture, although some decrease was also observed in the control treatment that may depend on climatic conditions (Lösch et al. 1992). However, a sharp decrease in $\Psi \mathrm{h}$ (down to $58 \%$ ) was observed only at the heading stage during the 21-day water deficit test, which was due to high plant water requirement. Indeed, soil moisture reached values far below $20 \%$, which is characterized by $-1.5 \mathrm{MPa}$ of matrix potential and can be considered the permanent wilting point. In contrast, at both tillering and stem elongation soil moisture never reached values below $20 \%$ so that barley varieties did not undergo critical water deficit stress. Of the investigated development stages, heading was the most sensitive to water deficit stress, while stem elongation was the least affected. Plant water potential is a good indicator of water deficit stress and its magnitude is influenced by both soil water deficit as well as evaporative demand. This could be seen during heading, where the plant water potential was much lower than during tillering and elongation at similar soil water content values. The measured leaf water potentials are in good agreement with the results of Lösch et al. (1992), who found that leaf water potential of barley could decrease to $2.5 \mathrm{MPa}$ in fully irrigated treatments under warm sunny conditions and to values of -4.0 MPa in drought stressed treatments. Ben Naceur et al. (1999) revealed a leaf water potential of $-0.8 \mathrm{MPa}$ and a humidity of $18 \%$ under well-watered conditions, buta leaf water potential and a humidity rate of $-2.2 \mathrm{MPa}$ and close to $12 \%$, respectively, at boot swollen and anthesis stages, for plots subjected to water deficit stress. Reduced leaf water potential has a primary role in osmoregulation and maintenance of plant tissue water status. Under water stress, abscisic acid is produced in shoot and root tissue and starts ionic regulation of water status at cell and tissue levels. Therefore, it is a combination of osmotic stress, hormonal metabolism and ionic regulation that maintains plant water status at the cost of plant growth and leads to osmoregulation. Nonetheless, osmoregulation at the cost of plant growth is acceptable in dry environments to make crops drought tolerant and water use efficient even with reduced yield (Farooq et al. 2019). Nevertheless, maintaining a relatively constant leaf water potential when the soil is drying may be associated with a mechanism to avoid tissue dehydration (Chaves et al. 2002, Abid et al. 2018). This mechanism, observed at the tillering stage, could be explained by a high capacity to extract water from the soil and an efficient control of transpiration losses (Tardieu 2013, Fahad et al. 2017). Regarding the varieties, similar behavior was observed in Rihane and Martin at late water deficit stress conditions, whereas greater water use and reductions in moisture and leaf water potential were observed in Martin than Rihane.

The study of Al-Ajlouni et al. (2016) showed a huge impact of pre-anthesis water deficit on barley yield components due to water deficit stress during tillering and stem elongation stages, whereas in the Mediterranean zone cereal crops are exposed to frequent post-anthesis water deficit. Our results indicate that water deficit stress affects yield components to varying degrees, according to the development stages. In general, all treatments negatively affected yield parameters, but water deficit stress during the heading stage had the most detrimental effects. This constraint at the heading stage led to the largest difference in crop development parameters. Several authors have reported the detrimental effect of water deficit stress at the anthesis period and its consequences for grain number per ear (Al-Ajlouni et al. 2016, Mahrookashani et al. 2017) and grain weight and size (Maiti and Satya 2014, Mahrookashani et al. 2017). Ben Naceur et al. (1999) in a wheat crop study demonstrated that water deficit stress caused a reduction of the yield parameters. When the water deficit occurred at the tillering stage, it mainly reduces the number of ears by surface unit, quantified in about $40 \%$. Moreover, it was 33\% and $17 \%$ respectively at swelling and anthesis stages, thereby reducing the weight of final yield. Consequently, whatever the stage during which the water deficit occurs, it affects both growth and yield. However, when it occurs just before heading (boot swollen), its consequences are the most harmful. During this period the ear is already formed, but the organ of flowering can be seriously damaged. Therefore, supplemental irrigation during this period is pivotal to mitigate the effects of water deficit stress. The decrease in NGE would be one of the most significant effects of water deficit stress (Honsdorf et al. 2017, Senapati et al. 2019). Our results are supported by a previous study by Saedi et al. (2012), which showed that water deficit during the grain filling stages significantly reduced WTG and thus grain yield, especially in more sensitive varieties. Breeders tend to breed barley varieties that can cope with water deficit during the most critical development stage before the beginning of grain filling, which is essential for the determination of grain number (Francia et al. 2013).

Our study indicated that NGE, NEP and WTG were reduced by more than $50 \%$ under water deficit conditions in the later stages. It should be noted that the same decrease in leaf water potential and in grain yield was recorded during the heading stage $(50 \%)$ underwater deficit. These reductions could be explained by sterile pollen or decreased pollen numbers reducing the final grain number per ear (Fahad et al. 2017, Honsdorf et al. 2017), or by the high accumulation of abscisic acid in the ear (Dong et al. 2017). According toDong et al. (2014), water deficit induces pollen sterility and, consequently, reduces the number of grains. This effect can be hypothesized in both Martin and Rihane. 
At the tillering stage, water deficit stress did not significantly affect the plants, suggesting that the studied varieties could overcome water-deficit periods and resume growth after rehydration. Moreover, a greater adaptation to water deficit stress at tillering was observed in Martin than in Rihane, which was quantified in both higher NEP and NGE. Farooq et al. (2019) reported that significant genetic variation exists among crops or within genotypes of the same crop for water use efficiency, suggesting the need to tailor more water-efficient genotypes. When the water deficit stress period ceased, even small amounts of water could have significant impacts on plant physiological functions (Tambussi et al. 2005). In this context, Abid et al. (2018) and Boguszewska-Mańkowska et al. (2018) showed that drought-tolerant plants, as opposed to drought-sensitive plants, were able to produce a high quantity of dry matter after rehydration. Thus, in the case of severe water deficit at the tillering and elongation periods, irrigation is recommended for farmers.

\section{Conclusions}

The aim of this study was to investigate the effect of water deficit and its timing on barley yields. Water deficit stress led to a gradual decline in leaf water potential and a decrease in yield components. However, plant responses depended on the time of stress application (stage) and its intensity (number of dry days). The effects of water deficit on yield were more pronounced when it occurred at the heading stage of the two studied varieties, an old (Martin) and a recent (Rihane) one, as suggested by the lowest water potential reduction at the heading stage under soil moisture conditions comparable with the tillering and elongation ones. A leaf water potential reduction of $50 \%$ at the heading stage during 21 days of water deficit stress generated the same reduction in grain yield (50\%). This may be explained by the low ca-

\section{References}

Abid, M., Ali, S., Qi, L.K., Zahoor, R., Tian, Z., Jiang, D., Snider, J.L., Dai, T., 2018: Physiological and biochemical changes during drought and recovery periods at tillering and jointing stages in wheat (Triticum aestivum L.). Scientific Reports 8, 4615.

Al-Ajlouni, Z., Al-Abdallat, A., Al-Ghzawi, A., Ayad, J., Abu Elenein, J., Al-Quraan, N., Baenziger, P., 2016: Impact of preAanthesis water deficit on yield and yield components in Barley (Hordeum vulgare L.) plants grown under controlled conditions. Agronomy 6, 33.

Balkovič, J., Skalský, R., Folberth, C., Khabarov, N., Schmid, E., Madaras, M., Obersteiner, M., van der Velde, M., 2018: Impacts and uncertainties of $+2^{\circ} \mathrm{C}$ of climate change and soil degradation on European crop calorie supply. Earth's Future 6, 373-395.

Bashir, M.U., Wajid, S.A., Ahmad, A., Awais, M., Raza, M.A.S., Tahir, G.M., Saeed, U., Rehman, M.H.U., Waqas, M., Abbas, S., 2017: Irrigation scheduling of wheat at different nitrogen levels in semi-arid region. Turkish Journal of Field Crops 22, 63-70.

Ben Naceur, A., Cheikh-M'hamed, H., Abdelly, C., Ben Naceur, M., 2018: Screening of north african barley genotypes for drought tolerance based on yields using tolerance indices un- pacity of the plant to recover growth when the water deficit stress occurred during a late plant development phase. The stage considered the most sensitive - heading - is the one when the leaf area was expectedly the largest. Additionally, at this time of the cycle plants are more advanced and may suffer from increased temperatures during the late growing season, which might partially compromise a full comparison between development stages. Irrigation in this period can help to increase the resistance of barley cultivars to water deficit conditions and improve grain yield in the Mediterranean zone. This work shows that if it is possible to reduce and to manage the amount of irrigation water in the semi-arid zone, irrigation will be economically more gainful because supplemental irrigation during dry periods is more efficient at the heading stage. The use of less water through thecereal cropping season helps countries to save their water. However, additional experiments under fully controlled conditions will provide a better understanding of the plant response to water stress conditions.

Martin barley, which is an old variety, performed better than Rihane in terms of weight of a thousand grains and has had traits of tolerance to water deficit since its creation. These characteristics improved over time because it has increasingly adapted to a semi-arid environment. These results highlight the fact that old varieties should be promoted as a means to preserve their genetic heritage, and used for improving adaptation to changing climatic conditions.

\section{Acknowledgments}

Authors are grateful to Dr. Hatem Cheikh M'Hamed, National Institute of Agronomic Research of Tunisia. This study was supported by the National Institute of Agronomic Research - Tunisia (INRAT).

der water deficit conditions. Turkish Journal of Field Crops23, 135-145.

Ben Naceur, M., Naily, M., Selmi, M. 1999: Effet d'un deficit hydrique, survenant a differents stades de developpement du ble, sur l'himidité du sol, la physiologie de la plante et sur les composantes du rendement. Medit 10, 53-60.

Boguszewska-Mańkowska, D., Pieczyński, M., Wyrzykowska, A., Kalaji, H.M., Sieczko, L., Szweykowska-Kulińska, Z., Zagdańska, B., 2018: Divergent strategies displayed by potato (Solanum tuberosum L.) cultivars to cope with soil drought. Journal of Agronomy and Crop Science 204, 13-30.

Cattivelli, L., Ceccarelli, S., Romagosa, I., Stanca, M., 2011: Abiotic stresses in Barley: Problems and solutions. Plant Cell and Environment 31, 11-38.

Chaves, M.M., Pereira, J.S., Maroco, J., Rodrigues, M.L., Ricardo, C.P.P., Osorio, M.L., Carvalho, I., Faria, T., Pinheiro, C., 2002: How plants cope with water stress in the field? Photosynthesis and growth. Annals of Botany 89, 907-916.

Deghaïs, M., Kouki, M., Gharbi, M.S., El Felah, M., 2007: Les variétés de céréales cultivées en Tunisie. Ministry of Agriculture and Water Resources, Tunis. 
Dong, B., Zheng, X., Liu, H., Able, J.A., Yang, H., Zhao, H., Zhang, M., Qiao, Y., Wang, Y., Liu, M., 2017: Effects of drought stress on pollen sterility, grain yield, abscisic acid and protective enzymes in two winter wheat cultivars. Frontiers in Plant Science 8, 1008.

Dong, J., Beard, J.D., Umbach, D.M., Park, Y., Huang, X., Blair, A., Kamel, F., Chen, H., 2014: Dietary fat intake and risk for Parkinson's disease. Movement Disorders: Official Journal of the Movement Disorder Society 29, 1623-1630.

Fahad, S., Bajwa, A.A., Nazir, U., Anjum, S.A., Farooq, A., Zohaib, A., Sadia, S., Nasim, W., Adkins, S., Saud, S., Ihsan, M.Z., Alharby, H., Wu, C., Wang, D., Huang, J., 2017: Crop production under drought and heat stress: Plant Responses and Management Options. Frontiers in Plant Science 8, 1147.

Farooq, M., Hussain, M., Ul-Allah, S., Siddique, K.H.M., 2019: Physiological and agronomic approaches for improving water-use efficiency in crop plants. Agricultural Water Management 219, 95-108.

Francia, E., Tondelli, A., Rizza, F., Badeck, F.W., Thomas, W.T.B., Van Eeuwijk, F., Romagosa, I., Stanca, A.M., Pecchioni, N., 2013: Determinants of barley grain yield in drought-prone Mediterranean environments. Italian Journal of Agronomy $8,1-8$.

Gammans, M., Mérel, P., Ortiz-Bobea, A., 2017: Negative impacts of climate change on cereal yields: statistical evidence from France. Environmental Research Letters 12, 054007.

Giannakopoulos, C., Le Sager, P., Bindi, M., Moriondo, M., Kostopoulou, E., Goodess, C.M., 2009: Climatic changes and associated impacts in the Mediterranean resulting from a $2 \mathrm{C}$ global warming. Global and Planetary Change 68, 209-224.

Honsdorf, N., March, T.J., Pillen, K., 2017: QTL controlling grain filling under terminal drought stress in a set of wild barley introgression lines. PLOS ONE 12, e0185983.

Lösch, R., Jensen, C.R., Andersen, M.N., 1992: Diurnal courses and factorial dependencies of leaf conductance and transpiration of differently potassium fertilized and watered field grown barley plants. Plant and Soil 140, 205-224.

Mahrookashani, A., Siebert, S., Hüging, H., Ewert, F., 2017: Independent and combined effects of high temperature and drought stress around anthesis on wheat. Journal of Agronomy and Crop Science 203, 453-463.

Maiti, R., K., Satya, P., 2014: Research advances in major cereal crops for adaptation to abiotic stresses. GM Crops \& Food 5, 259-279.

Malek, Ž., Verburg, P.H., 2018: Adaptation of land management in the Mediterranean under scenarios of irrigation water use and availability. Mitigation and Adaptation Strategies for Global Change 23, 821-837.

Mansouri, S., Radhouane, L., 2015: Dynamique du climat et impact sur la production d'orge dans la zone de béja au nordouest de la Tunisie.European Scientific Journal 11, 85-103.

Meng, W., Yu, Z., Zhao, J., Zhang, Y., Shi, Y., 2017: Effects of supplemental irrigation based on soil moisture levels on photosynthesis, dry matter accumulation, and remobilization in winter wheat (Triticum aestivum L.) cultivars. Plant Production Science 20, 215-226.

Moriondo, M., Giannakopoulos, C., Bindi, M. 2011: Climate change impact assessment: the role of climate extremes in crop yield simulation. Climatic Change 104, 679-701.

Morison, J.I.L., Baker, N.R., Mullineaux, P.M., Davies, W.J., 2008: Improving water use in crop production. Philosophical Transactions of the Royal Society B. Biological Sciences 363, 639-658.

Mougou, R., Mansour, M., Iglesias, A., Chebbi, R.Z., Battaglini, A., 2011: Climate change and agricultural vulnerability: a case study of rain-fed wheat in Kairouan, Central Tunisia. Regional Environmental Change 11, 137-142.

Olesen, J.E., Trnka, M., Kersebaum, K.C., Skjelvåg, A.O., Seguin, B., Peltonen-Sainio, P., Rossi, F., Kozyra, J., Micale, F., 2011: Impacts and adaptation of European crop production systems to climate change. European Journal of Agronomy 34, 96-112.

Ouji, A., Rouaissi, M., Ben Salem, M., 2018: Comportement varietale de lorge (Hordeum vulgare L.) an double exploitation. Annales de l'INRAT 83, 103-117.

Perniola, M., Lovelli, S., Arcieri, M., Amato, M., 2015: Sustainability in Cereal Crop Production in Mediterranean Environments. In: Vastola, A. (ed), The sustainability of agro-food and natural resource systems in the Mediterranean Basin, 1527. Springer, Cham.

Rochdane, S., Bounoua, L., Zhang, P., Imhoff, M., Messouli, M., Yacoubi-Khebiza, M., Rochdane, S., Bounoua, L., Zhang, P., Imhoff, M.L., Messouli, M., Yacoubi-Khebiza, M., 2014: Combining satellite data and models to assess vulnerability to climate change and its impact on food security in Morocco. Sustainability 6, 1729-1746.

Romdhane, L., Dal Cortivo, C., Vamerali, T., Radhouane, L., 2016: Effects of drought and salinity on maize phenology, morphology and productivity in a semi-arid environment. Italian Journal of Agrometeorology 21, 43-54.

Saedi, M., Moradi, F., Jalali-Honarmand, S., 2012: The effect of post anthesis source limitation treatments on wheat cultivars under water deficit. Australian Journal of Crop Science 6, 1179-1187.

Scholander, P.F., Bradstreet, E.D., Hemmingsen, E.A., Hammel, H.T., 1961: Cohesive lift of sap in the rattan vine: The problem of how sap rises lies stranded for lack of means to measure negative pressure in liquids. Science 134, 1835-1838.

Senapati, N., Stratonovitch, P., Paul, M.J., Semenov, M.A., 2019: Drought tolerance during reproductive development is important for increasing wheat yield potential under climate change in Europe. Journal of Experimental Botany70, 25492560.

Slama, A., Mallek-Maalej, E., Ben Mohamed, H., Rhim, T., Radhouane, L., 2018: A return to the genetic heritage of durum wheat to cope with drought heightened by climate changePLOS ONEhttps://doi.org/10.1371/journal.pone.0196873.

Stevanović, M., Popp, A., Lotze-Campen, H., Dietrich, J.P., Müller, C., Bonsch, M., Schmitz, C., Bodirsky, B.L., Humpenöder, F., Weindl, I., 2016: The impact of high-end climate change on agricultural welfare. Science Advances 2, e1501452.

Sultan, B., 2012: Global warming threatens agricultural productivity in Africa and South Asia. Environmental Research Letters 7, 041001.

Tambussi, E.A., Nogués, S., Araus, J.L., 2005: Ear of durum wheat under water stress: water relations and photosynthetic metabolism. Planta 221, 446-458.

Tardieu, F., 2013: Plant response to environmental conditions: assessing potential production, water demand, and negative effects of water deficit. Frontiers in Physiology 4, 17.

Wang, D., 2017: Water use efficiency and optimal supplemental irrigation in a high yield wheat field. Field Crops Research 213, 213-220.

Zhang, S., Gho, L., Han, L., Li, F., Jin, L., Xiao, K., 2019: The effects of $\mathrm{n}$ input level on $\mathrm{n}$ uptake, remobilization and agronomic traits under deficit irrigation condition in winter wheat. Turkish Journal of Field Crops24, 111-120. 